\title{
Influences of Polyol on the Chemical, Thermal, and Mechanical Properties of Polyurethane Elastomers Crosslinked by $\beta$-Cyclodextrin
}

\author{
Yingjie Chen $^{1}$, An Xie ${ }^{1}$, Ming Zhang ${ }^{2}$, Shin-Ichi Inoue ${ }^{1}$ \\ ${ }^{1}$ Department of Applied Chemistry, Aichi Institute of Technology, Toyota, Japan \\ ${ }^{2}$ School of Chemistry and Chemical Engineering, Yangzhou University, Jiangsu, China \\ Email: z15708zz@aitech.ac.jp
}

How to cite this paper: Chen, Y.J., Xie, A., Zhang, M. and Inoue, S.-I. (2017) Influences of Polyol on the Chemical, Thermal, and Mechanical Properties of Polyurethane Elastomers Crosslinked by $\beta$-Cyclodextrin. Open Journal of Organic Polymer Materials, 7, 29-46.

https://doi.org/10.4236/ojopm.2017.73003

Received: January 17, 2017

Accepted: July 25, 2017

Published: July 28, 2017

Copyright $\odot 2017$ by authors and Scientific Research Publishing Inc. This work is licensed under the Creative Commons Attribution International License (CC BY 4.0).

http://creativecommons.org/licenses/by/4.0/ (c) (i) Open Access

\begin{abstract}
A series of polyurethane elastomers (PUEs) were synthesized from an aromatic diisocyanate (4, 4'-diphenylmethane diisocyanate); a polyether polyol (polytetramethylene glycol, molecular weight: 1000), polyester polyol (polycaprolactonediol, molecular weight: 1000 , or polycarbonate diol, molecular weight: 1000); and $\beta$-cyclodextrin ( $\beta$-CD) as a cross-linker. The effect of the polyol on the morphologies and chemical, thermal, and mechanical properties of the resultant $\beta$-CD-based PUEs were investigated in this study. The obtained films were characterized via solubility and swelling tests (chemical properties), differential scanning calorimetry (crystallinity degree), dynamic mechanical analysis (thermal stability), thermogravimetric analysis (thermal stability), tensile testing (mechanical properties), nuclear magnetic resonance spectroscopy, infrared spectroscopy, atomic force microscopy (morphology), contact angle determination (morphology), and scanning electron microscopy (morphology).
\end{abstract}

\section{Keywords}

Polyurethane Elastomer (PUE), $\beta$-Cyclodextrin ( $\beta$-CD), Polyol (PTMG, PCL, PCD), Morphology, Chemical and Physical Properties

\section{Introduction}

Polyurethanes (PUs) are versatile engineering materials used in a wide range of applications because their properties can be readily tailored according to the type and composition of their components [1] [2] [3]. PUs are used commercially in seven major product types [4]-[9]: 1) flexible slabs; 2) flexible molded 
foams; 3) rigid foams; 4) solid elastomers; 5) reaction injection molded materials; 6) carpet backings; and 7) one- and two-component formulations for coatings, adhesives, and sealants. Considering the wide utilization of PU in daily life, researchers have continued to develop polymer materials with novel functionalities. Various studies have used natural products as raw materials [10]-[22], initiators [23] [24] [25], and coating agents [26] [27] [28]. In addition, polyurethane elastomers (PUEs) containing natural products have been used as biocompatible materials in the medical field [29] [30].

In this work, we focus on the synthesis of PUEs containing $\beta$-CD as a natural product. PUEs containing $\beta$-CD may be used for many purposes, such as heat insulation, tremor insulation, and cases for commercial instruments. We recently synthesized PUEs containing $\beta$-CD by the prepolymer method [31] [32] [33]. Polyaddition of isocyanate and polyol to form PUEs has rarely been applied to prepare PUEs. Hence, the synthesis of PUEs using various polyols via polyaddition remains a challenging subject in polymer chemistry. In this article, we report the synthesis of $\beta$-CD-containing PUEs using an aromatic isocyanate $(4,4$ 'diphenylmethane diisocyanate (MDI)), polyether polyol (PTMG1000), and polyester polyols (PCL1000 and PCD1000) with $\beta$-CD as a cross-linker via the prepolymer method. The morphologies and chemical, thermal, and mechanical properties of the obtained PUEs are then studied.

\section{Experimental}

\subsection{Materials}

Polytetramethylene glycol (molecular weight: 1000; PTMG1000) was supplied by Invista Industry, Texas, USA. Polycaprolactonediol (molecular weight: 1000; PCL 1000 ) and polycarbonate diol (molecular weight: 1000; PCD1000) were supplied by Tosoh Industry, Tokyo, Japan. The polyols were dehydrated in vacuo at $80^{\circ} \mathrm{C}$ for $24 \mathrm{~h}$ before use. 4, 4'-Diphenylmethane diisocyanate (MDI) was supplied by Tosoh Industry and purified by distillation under reduced pressure $(267-400 \mathrm{~Pa})$ at $100^{\circ} \mathrm{C}$ before use. $\beta$-CD was purchased from Nacalai Tesque, Inc., Kyoto, Japan, and dried for $24 \mathrm{~h}$ under reduced pressure $(267-400 \mathrm{~Pa})$ at $80^{\circ} \mathrm{C}$ before use. Tetrahydrofuran (THF) and benzene were also purchased from Nacalai and distilled over calcium hydride under an Ar atmosphere. $N, N$-Dimethylformamide (DMF) and dimethyl sulfoxide (DMSO) were purchased from Nacalai and stored over $4 \AA$ molecular sieves before use. Hexane and acetone, both obtained from Nacalai, were used as received.

\subsection{Synthesis}

A series of $\beta$-CD-based PUEs were synthesized from MDI, a polyol (PTMG1000, PCL1000, or PCD1000), and $\beta$-CD via the prepolymer method (Scheme 1). The composition and $\beta$-CD content of each PUE are listed in Table 1. The PUEs obtained were named PUE-X-CDy, where $\mathrm{X}$ refers to the type of polyol used and $\mathrm{y}$ refers to the weight percent (wt\%) of $\beta$-CD added. Synthesis was performed as 


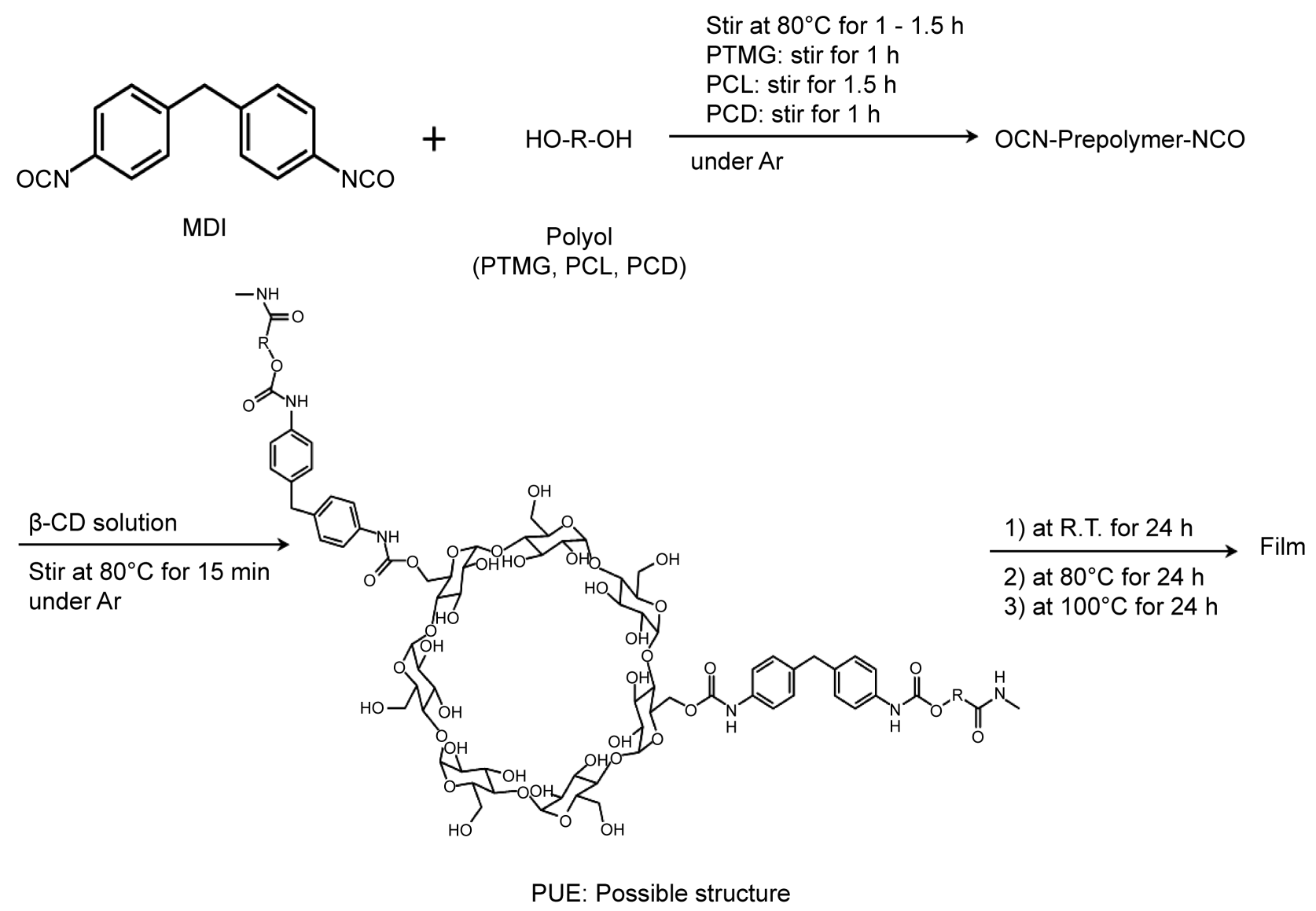

Scheme 1 . Synthesis of polyurethane elastomers containing $\beta$-Cyclodextrin by prepolymer method.

Table 1. Recipe of PUEs with $\beta$-CD.

\begin{tabular}{|c|c|c|c|}
\hline Sample & MDI (mol) & PTMG·PCL·PCD (mol) & $\beta-\mathrm{CD}\left(\times 10^{-3} \mathrm{~mol}\right)$ \\
\hline PUE-Polyol-CD ${ }_{0}$ & 0.020 & 0.010 & - \\
\hline PUE-Polyol-CD ${ }_{1}$ & 0.020 & 0.010 & 0.15 \\
\hline PUE-Polyol-CD ${ }_{2}$ & 0.020 & 0.010 & 0.31 \\
\hline PUE-Polyol-CD ${ }_{3}$ & 0.020 & 0.010 & 0.46 \\
\hline PUE-Polyol-CD ${ }_{5}$ & 0.020 & 0.010 & 0.79 \\
\hline
\end{tabular}

follows: a solution of $\beta$-CD and DMF $(10 \mathrm{~mL})$ was prepared and heated at $80^{\circ} \mathrm{C}$ for $20 \mathrm{~min}$ under an Ar atmosphere. MDI (5.0 g, $0.020 \mathrm{~mol}$ ) and various polyols (PTMG1000, PCL1000, or PCD1000; $10 \mathrm{~g}$ each, $0.010 \mathrm{~mol}$ ) were added to a 100 $\mathrm{mL}$ four-necked separable reaction flask equipped with a mechanical stirrer, a gas inlet tube, and a reflux condenser. The prepolymers were prepared at $80^{\circ} \mathrm{C}$ for $1 \mathrm{~h}$ (PTMG1000) or $2 \mathrm{~h}$ (PCL1000 and PCD1000) with stirring under an Ar atmosphere, after which $10 \mathrm{~mL}$ of the $\beta$-CD solution was added to them. The reaction mixture was heated at $80^{\circ} \mathrm{C}$ for 15 min with stirring. Bubbles in the system were removed by addition of THF $(20 \mathrm{~mL})$ and high-speed stirring for 5 
min. Thin PUE films $(0.7-0.8 \mathrm{~mm})$ were obtained by casting the resulting PUE solutions (about $50 \mathrm{~mL}$ each) at room temperature $\left(23^{\circ} \mathrm{C} \pm 2^{\circ} \mathrm{C}\right)$ for $24 \mathrm{~h}$, at $50^{\circ} \mathrm{C}$ for $24 \mathrm{~h}$, and at $100^{\circ} \mathrm{C}$ for $24 \mathrm{~h}$. DMF residues in the films were removed at $80^{\circ} \mathrm{C}$ for $6 \mathrm{~h}$ in vacuo.

\subsection{Characterization}

\subsubsection{Nuclear Magnetic Resonance (NMR) Spectroscopy}

${ }^{1} \mathrm{H}$ nuclear magnetic resonance (NMR; $\left.300 \mathrm{MHz}\right)$ and ${ }^{13} \mathrm{C}$ NMR $(75.4 \mathrm{MHz})$ spectra were recorded on a Varian Unity Plus-300 spectrometer by using the solid-state method.

\subsubsection{Fourier Transform Infrared (FTIR) Spectroscopy}

FTIR spectra were recorded on a JASCO (Tokyo, Japan) FTIR-5300 spectrometer equipped with an attenuated total reflection (ATR) system featuring an ATR500/ $\mathrm{M}$ attachment and a KRS-5 ATR prism.

\subsubsection{Morphological Analyses}

Contact angle (CA) measurements were performed on dried films at room temperature $\left(23^{\circ} \mathrm{C} \pm 2^{\circ} \mathrm{C}\right)$ in air using an Excimer (Yokohama, Japan) Image Standard 100 system. Samples of $5 \mu \mathrm{L}$ were dripped.

The dried films were subjected to atomic force microscopy (AFM) at room temperature $\left(23^{\circ} \mathrm{C} \pm 2^{\circ} \mathrm{C}\right)$ in air using an Olympus (Tokyo, Japan) NV2000 system. Most of the images were obtained in tapping mode (ACAFM) with a silicon nitride cantilever (OMMCL-AC 240TS-C2, Olympus Optical) using a spring constant of $15 \mathrm{~N} / \mathrm{m}$ and a resonating frequency of $20 \mathrm{KHz}$. The scanning rates were varied from $1 \mathrm{~Hz}$ to $2 \mathrm{~Hz}$, and all images presented here were reproduced from images obtained from at least three points on each sample surface.

SEM was used to observe the surface morphology of the PUEs with a Hitachi High-Technologies S-4800 (Tokyo, Japan) system. All micrographs were taken at a magnification of $30 \mathrm{~K} \times$.

\subsubsection{Chemical Property}

Swelling tests were carried out in THF. The PUE films were cut into $10 \times 20$ $\mathrm{mm}^{2}$ samples. After weighing, the films were placed in a test tube with THF solution for $24 \mathrm{~h}$. Thereafter, the films were removed from the tubes, dried, and then weighed once more. The degree of swelling (Rs) was calculated using the formula $\mathrm{Rs}(\%)=\mathrm{W}^{\prime}-\mathrm{W} / \mathrm{W} \times 100$, where $\mathrm{W}$ and $\mathrm{W}^{\prime}$ refer to the weights of the samples before and after soaking, respectively.

Solubility tests were performed using $15 \times 15 \mathrm{~mm}^{2}$ test pieces. Each test piece was soaked in a solvent (benzene, hexane, acetone, THF, DMF, or DMSO; $6 \mathrm{~mL}$ ) at room temperature $\left(23^{\circ} \mathrm{C} \pm 2^{\circ} \mathrm{C}\right.$ ) or $100^{\circ} \mathrm{C}$ (for DMF and DMSO) for $24 \mathrm{~h}$.

\subsubsection{Mechanical Properties}

Hardness was tested by using an ASKER durometer (Kobunshi Keiki, Co., Takizawa, Japan) with the A scale, which is used for rubbers in the normal hardness 
range. The test procedure followed JIS K 6253.

Tensile tests were performed by using an ORIENTEC (Tokyo, Japan) RTC$1225 \mathrm{~A}$ universal tensile testing instrument equipped with a U-4300 extensometer. Samples were cut into dumbbell-shaped strips following the JIS K 6251-3 standard. Tensile tests were performed at a crosshead speed of $100 \mathrm{~mm} / \mathrm{min}$ at room temperature $\left(23^{\circ} \mathrm{C} \pm 2^{\circ} \mathrm{C}\right)$.

Dynamic mechanical analyses (DMA) were performed on a Seiko Instruments (Chiba, Japan) DMS 6100 at a heating rate of $5^{\circ} \mathrm{C} / \mathrm{min}$ from $-100^{\circ} \mathrm{C}$ to $300^{\circ} \mathrm{C}$ and at $20 \mathrm{~Hz}$ under a $\mathrm{N}_{2}$ atmosphere.

Thermogravimetric analyses (TGA) were performed on a Seiko Instruments TG/DTA6200 at a heating rate of $10^{\circ} \mathrm{C} / \mathrm{min}$ from $30^{\circ} \mathrm{C}$ to $500^{\circ} \mathrm{C}$ under a $\mathrm{N}_{2}$ atmosphere.

\subsubsection{Thermal Properties}

Differential scanning calorimetry (DSC) measurements were performed on a Rigaku (Tokyo, Japan) Thermo-Plus DSC-8230 system at a heating rate of $10^{\circ} \mathrm{C} / \mathrm{min}$ from $-120^{\circ} \mathrm{C}$ to $200^{\circ} \mathrm{C}$ under an Ar atmosphere. Approximately $5 \mathrm{mg}$ of each PUE was weighed and sealed in an aluminum pan. The samples were rapidly cooled to $-120^{\circ} \mathrm{C}$ and then heated to $200^{\circ} \mathrm{C}$ at a rate of $10^{\circ} \mathrm{C} / \mathrm{min}$.

\section{Results and Discussion}

\subsection{Nuclear Magnetic Resonance (NMR) Spectroscopy}

Solid-state ${ }^{1} \mathrm{H}$ NMR and ${ }^{13} \mathrm{C}$ NMR spectroscopy revealed that the polymers were undoubtedly PUEs containing $\beta$-CD and composed of a urethane segment and $\beta$-CD. NMR analyses indicated that $\beta$-CD was attached to the main PU chain as a cross-linker. For example, the solid-state ${ }^{1} \mathrm{H}$ NMR spectrum of PUE-PTMG$\mathrm{CD}_{1}$ showed peaks at $\delta 8.54(1 \mathrm{H}, \mathrm{CO}-\mathrm{NH}), 7.31$ and $7.08\left(1 \mathrm{H},-\mathrm{C}_{6} \mathrm{H}_{4}-\right), 5.10-4.27$ $(1 \mathrm{H},-\mathrm{CH}(\mathrm{OH})-), 4.05$ and $3.27\left(2 \mathrm{H},-\mathrm{O}-\mathrm{CH}_{2}-\right), 3.78\left(2 \mathrm{H},-\mathrm{C}_{6} \mathrm{H}_{4}-\mathrm{CH}_{2}-\mathrm{C}_{6} \mathrm{H}_{4}-\right)$, and $1.49\left(2 \mathrm{H},-\mathrm{CH}_{2}-\mathrm{CH}_{2^{-}},-\mathrm{CH}(\mathrm{R})-\right)$, and its solid-state ${ }^{13} \mathrm{C} \mathrm{CP} / \mathrm{TOSS} \mathrm{NMR}$ spectrum showed peaks at $1 \delta 64.0-147.2$ (urethane; $\mathrm{C}=\mathrm{O}$ ), (urea, $\mathrm{C}=\mathrm{O}$ ), 129.0 $(-\mathrm{C}=\mathrm{C}-), 118.0(-\mathrm{C}=\mathrm{C}-), 70.0\left(-\mathrm{O}-\mathrm{CH}_{2}-\right)$, and $20.2\left(-\mathrm{CH}_{2}-\right)$.

\subsection{Fourier Transform Infrared (FTIR) Spectroscopy}

FTIR measurements were utilized to determine the structure of the PUEs. Carbonyl $\mathrm{C}=\mathrm{O}$ group absorptions are shown in Figure 1. As PUE-PTMG- $\mathrm{CD}_{0-5}$ contains $\mathrm{C}=\mathrm{O}$ groups only in the urethane linkage, peaks at around 1708 and $1728 \mathrm{~cm}^{-1}$, corresponding to hydrogen-bonded $v\left(\mathrm{C}=\mathrm{O}_{\text {bonded }}\right)$ and free $v\left(\mathrm{C}=\mathrm{O}_{\text {free }}\right)$ carbonyl stretching vibrations, respectively, appeared. In PUE-PCL-CD $D_{0-5}$, another peak at around $1721 \mathrm{~cm}^{-1}$, corresponding to acidic $\mathrm{C}=\mathrm{O}$ groups in the PCL molecule, was observed. PUE-PCD-CD $D_{0-5}$ showed a peak at $1737 \mathrm{~cm}^{-1}$, thus proving the existence of the carbonate $\mathrm{C}=\mathrm{O}$ group in $\mathrm{PCD}$. These results reveal that PTMG, PCL, and PCD were successfully introduced to the PUE molecular chains. 

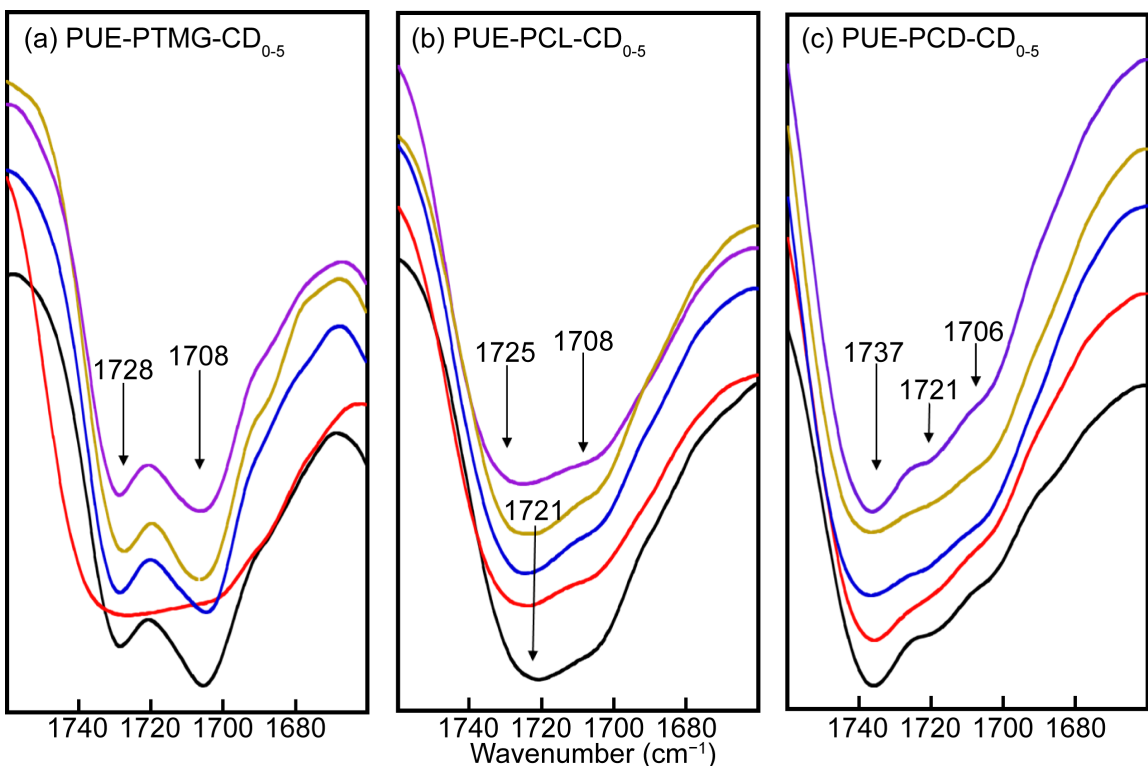

Figure 1. FTIR (ATR method) spectra of $\mathrm{C}=\mathrm{O}$ region of PUEs. (a) PUE-PTMG- $\mathrm{CD}_{0-5}$; (b) PUE-PCL-CD ${ }_{0-5}$; (c) PUE-PCD-CD $\mathrm{CD}_{0-5}$. $\beta$-CD content: black $=0 \mathrm{wt} \%$; red $=1 \mathrm{wt} \%$; blue = $2 \mathrm{wt} \%$; yellow $=3 \mathrm{wt} \%$; purple $=5 \mathrm{wt} \%$.

\subsection{Morphological Analyses}

The morphologies of the PUEs obtained were characterized by SEM, and images of PUE-PTMG-CD $0_{0-5}$, PUE-PCL-CD 0 , and PUE-PCD- $\mathrm{CD}_{0-5}$ are shown in Figures $2-4$, respectively. Phase segregation was observed in all of the images. As the $\beta$-CD content increased, the size of hard domains also increased. The surfaces of PUE-PCL-CD $D_{0-5}$ and PUE-PCD-CD $D_{0-5}$, especially those of PUE-PCL$\mathrm{CD}_{3}$, PUE-PCL-CD ${ }_{5}$, and PUE-PCD-CD $\mathrm{C}_{5}$, showed obvious agglomerations of hard domains, which is likely related to the structure of the polyol used. The images obtained reveal that PTMG presents a more regular structure than either PCL or PCD and, thus, features greater flexibility. When the PUEs were crosslinked with $\beta$-CD, the flexibility of the molecular chains of the PUEs decreased and the molecular chains of PUEs synthesized from the less-flexible polyols, such as PCL and PCD, become more rigid.

The surface topographies of the PUEs (PUE-PTMG-CD ${ }_{0-5}$, PUE-PCL-CD ${ }_{0-5}$, and PUE-PCD-CD $\mathrm{CD}_{0-5}$ ) were examined by AFM (Figures 5-7) to observe the phase-segregated morphology of the $\beta$-CD-based PUEs. AFM investigations were conducted on the surface of the polymers over a scanning area of $2 \times 2$ $\mu \mathrm{m}^{2}$. Topographical heterogeneity, which reflects the ordering tendency of the polymer structure, was observed in the images of PUEs with and without $\beta$-CD. In these images, by convention, hard and soft microphases appear as bright and dark regions, respectively. Increasing the hard segment concentration brought about noticeable changes in surface morphology. The presence of bright and dark regions indicates the presence of a microphase morphology. The AFM images of the PUE without $\beta$-CD revealed large portions featuring a smooth surface, whereas those of the PUE films with $\beta$-CD revealed smaller uneven surfaces. 

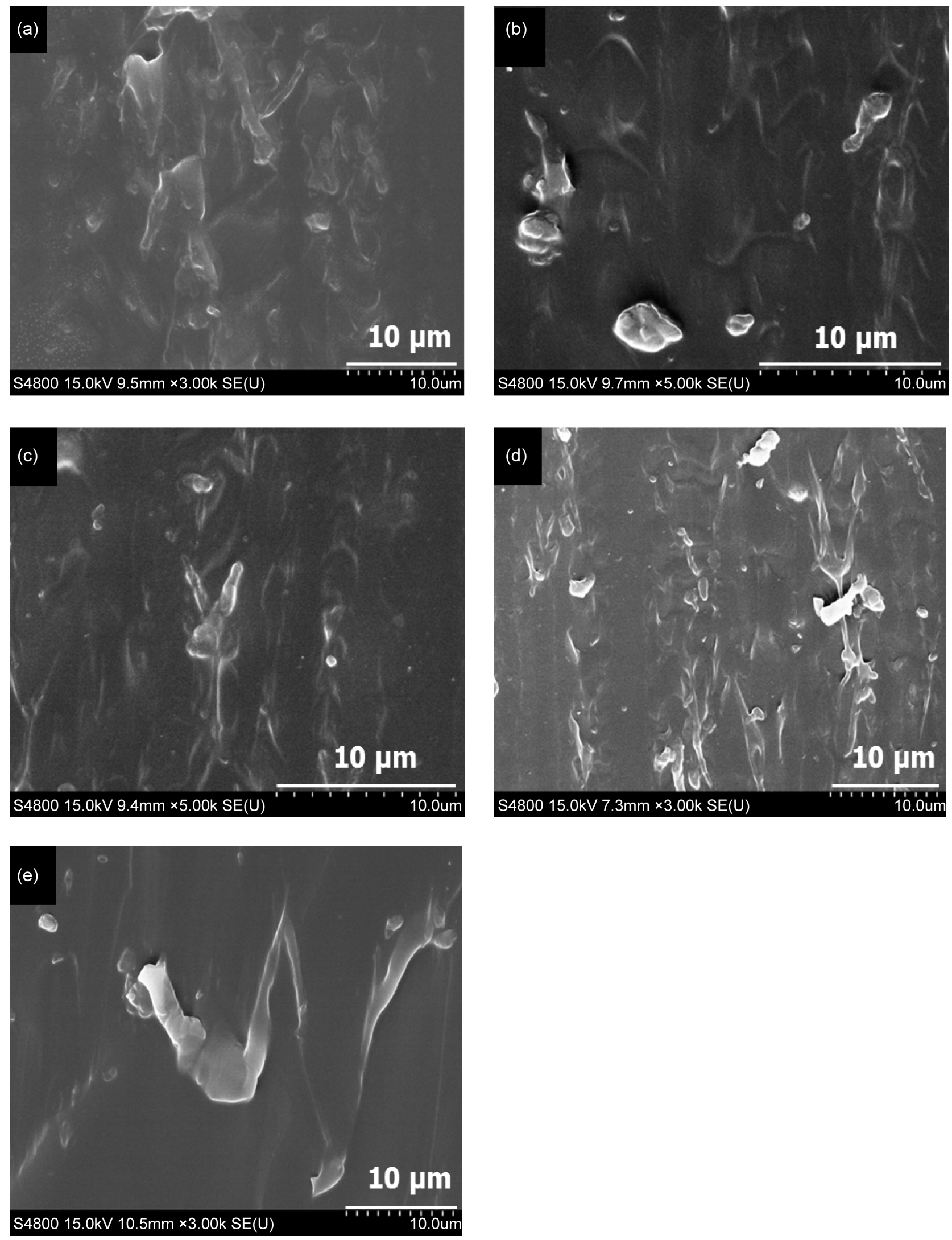

Figure 2. SEM micrographs of PUEs with $\beta$-CD. $\beta$-CD content: (a) PUE-PTMG-CD $=0$ wt\%; (b) PUE-PTMG-CD $1=1$ wt $\%$; (c) PUE-PTMG-CD $=2 \mathrm{wt} \%$; (d) PUE-PTMG-CD $3=3 \mathrm{wt} \%$; (e) PUE-PTMG-CD $=5 \mathrm{wt} \%$. 

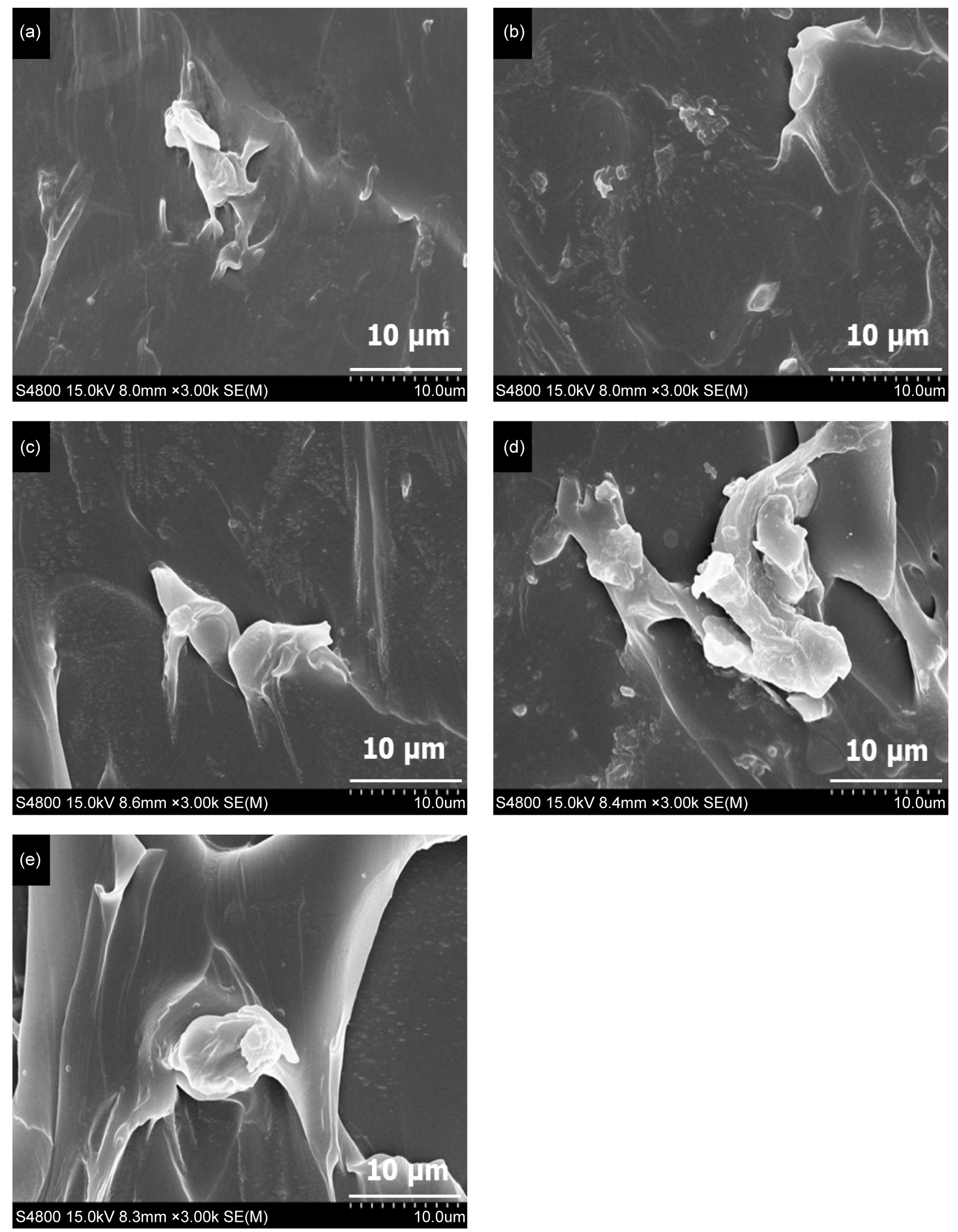

Figure 3. SEM micrographs of PUEs with $\beta$-CD. $\beta$-CD content: (a) PUE-PCL-CD $=0$ wt\%; (b) PUE-PCL-CD ${ }_{1}=1$ wt\%; (c) PUE-PCL-CD $=2 \mathrm{wt} \%$; (d) PUE-PCL-CD $3=3 \mathrm{wt} \%$; (e) PUE-PCL-CD $5=5 \mathrm{wt} \%$. 

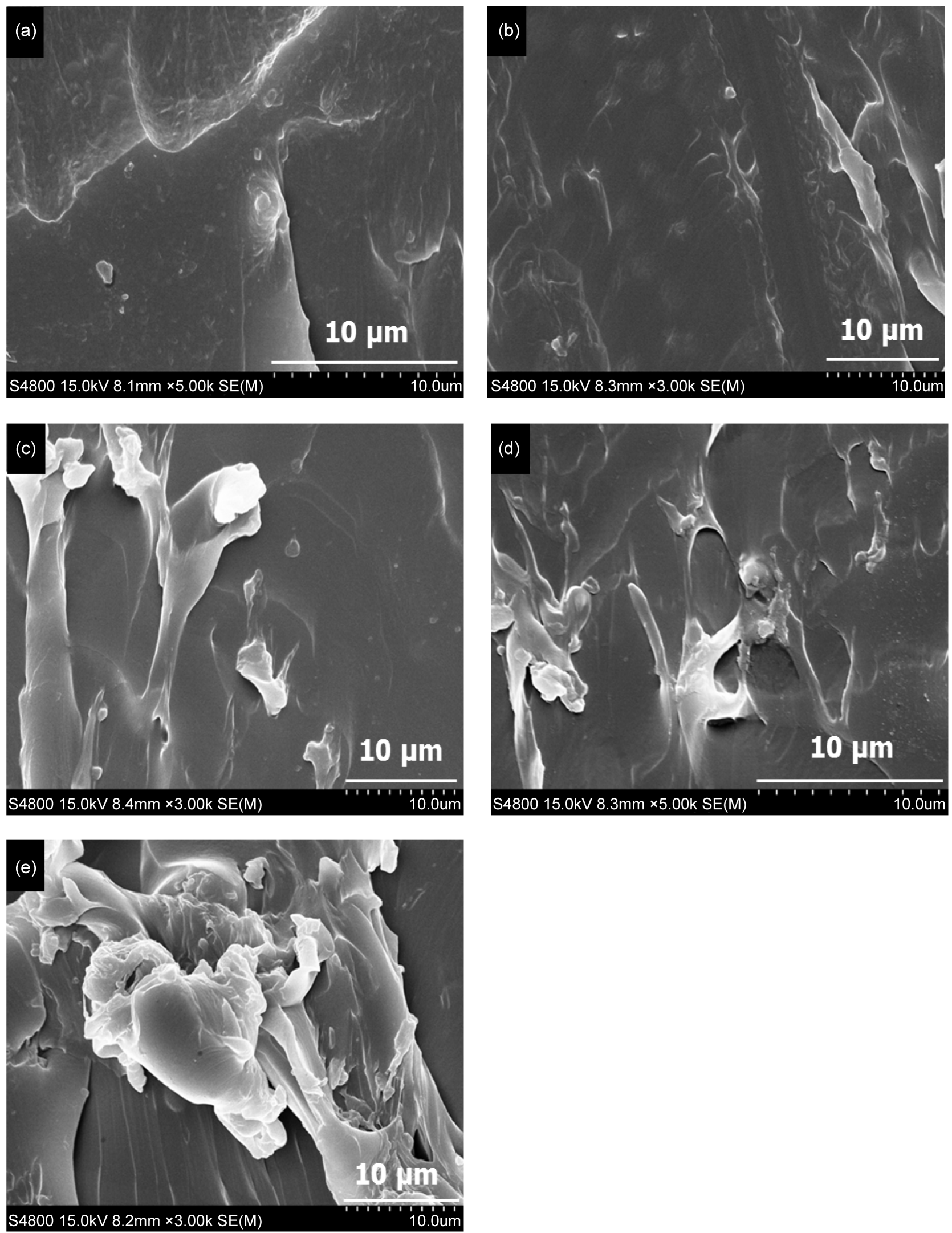

Figure 4. SEM micrographs of PUEs with $\beta$-CD. $\beta$-CD content: (a) PUE-PCD-CD $=0$ wt $\%$; (b) PUE-PCD-CD $=1$ wt $\%$; (c) PUE-PCD-CD $=2 \mathrm{wt} \%$; (d) PUE-PCD-CD $=3 \mathrm{wt} \%$; (e) PUE-PCD-CD $\mathrm{CD}_{5}=5 \mathrm{wt} \%$. 

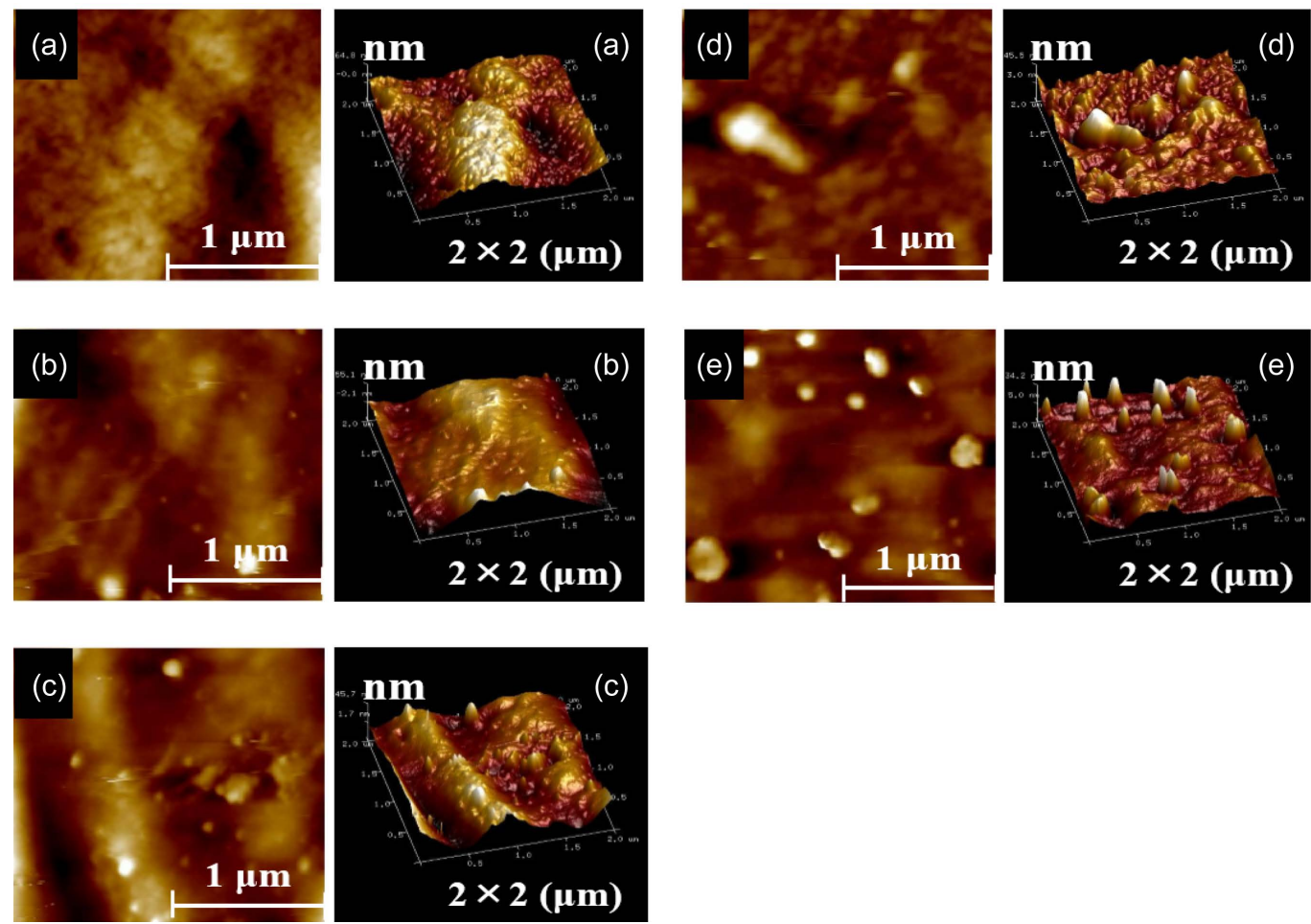

Figure 5. Topographic and three dimensional AFM images of PUEs with $\beta$-CD. $\beta$-CD content: (a) PUE-PTMG-CD $=0 \mathrm{wt} \%$; (b) PUE-PTMG-CD $=1 \mathrm{wt} \%$; (c) PUE-PTMG-CD $=2 \mathrm{wt} \%$; (d) PUEPTMG-CD $3=3 \mathrm{wt} \%$; (e) PUE-PTMG-CD $=5 \mathrm{wt} \%$.
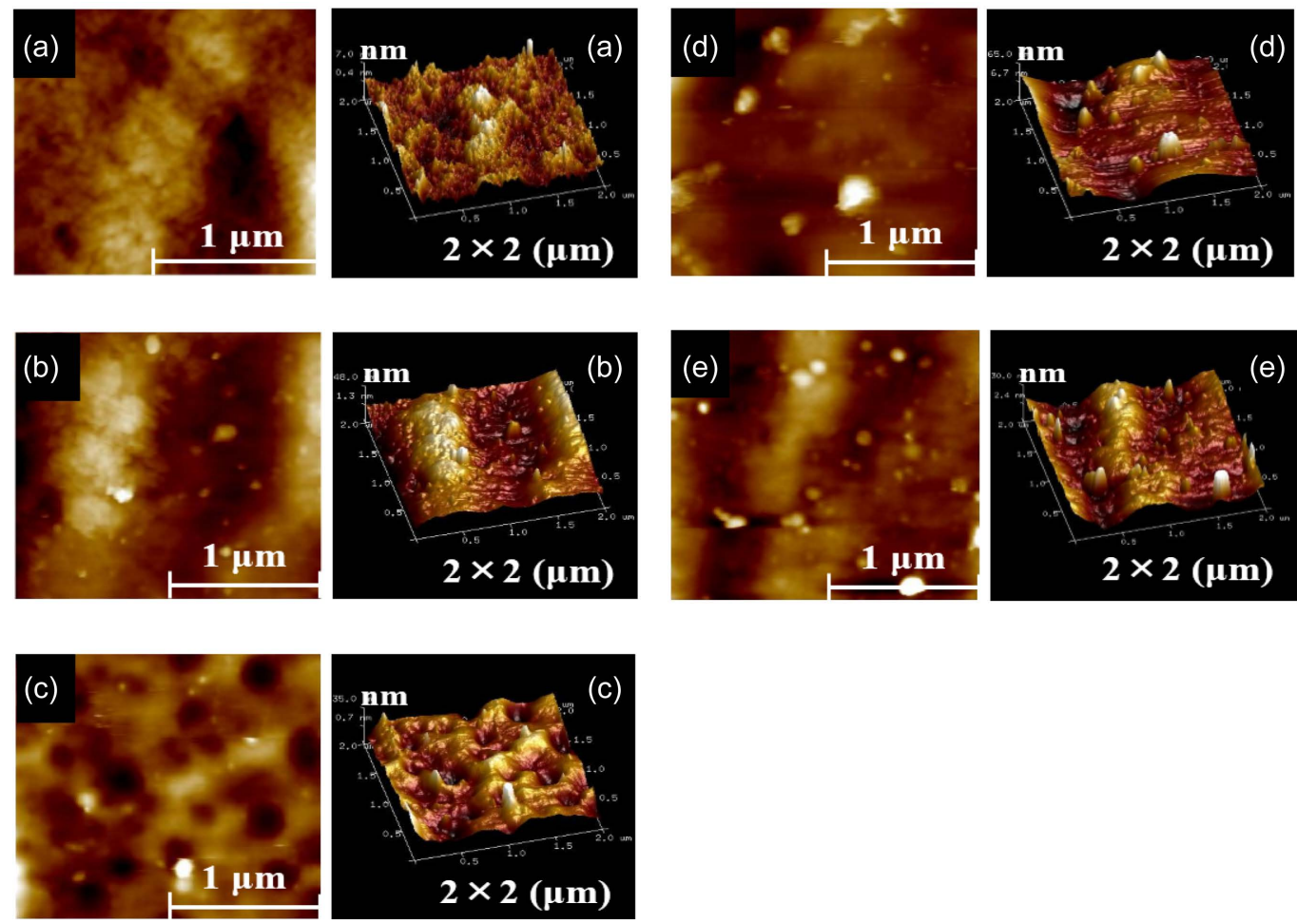

Figure 6. Topographic and three dimensional AFM images of PUEs with $\beta$-CD. $\beta$-CD content: (a) PUE-PCL-CD $=0 \mathrm{wt} \%$; (b) PUE-PCL-CD $1=1 \mathrm{wt} \%$; (c) PUE-PCL-CD ${ }_{2}=2 \mathrm{wt} \%$; (d) PUE-PCL-CD ${ }_{3}=3$ wt\%; (e) PUE-PCL-CD $5=5$ wt $\%$. 

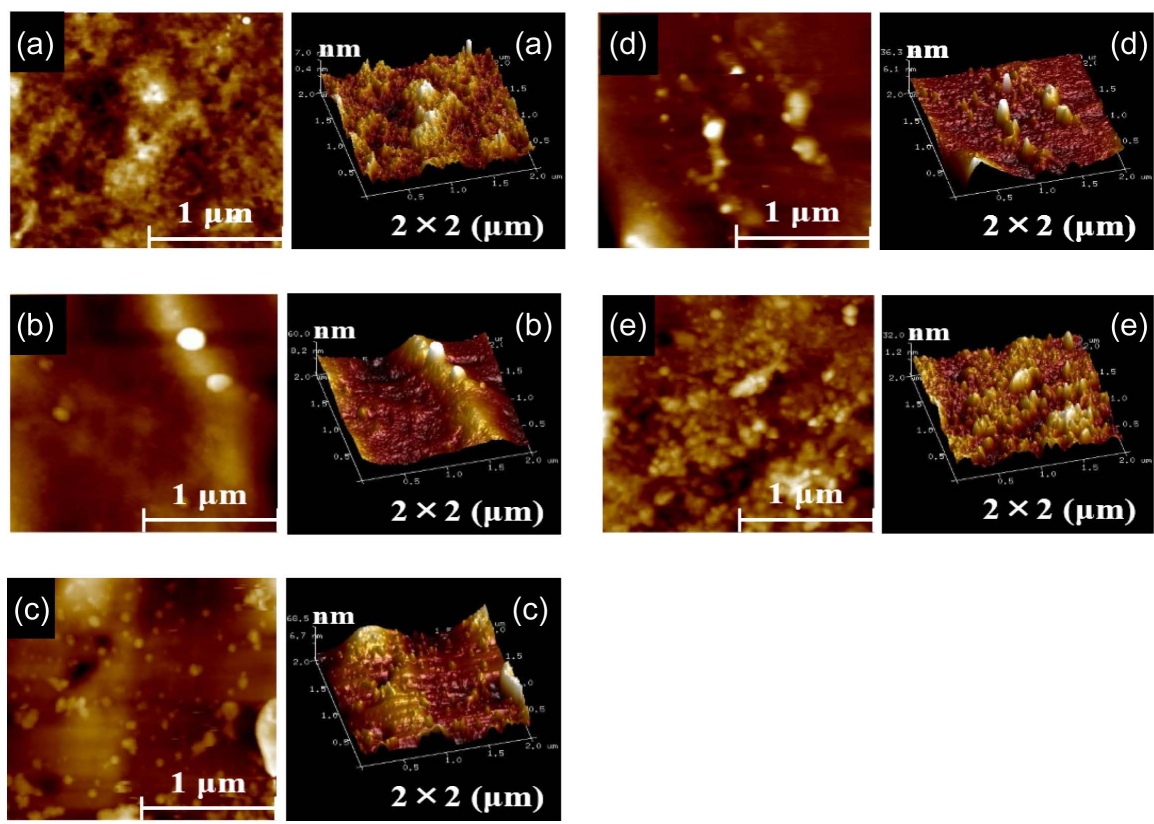

Figure 7. Topographic and three dimensional AFM images of PUEs with $\beta$-CD. $\beta$-CD content: (a) PUE-PCD-CD $=0 \mathrm{wt} \%$; (b) PUE-PCD-CD $1=1 \mathrm{wt} \%$; (c) PUE-PCD-CD $=2$ wt $\%$; (d) PUE-PCD-CD $3=3 \mathrm{wt} \%$; (e) PUE-PCD-CD $5=5 \mathrm{wt} \%$.

Light-colored spots representing hard segments were dispersed all over the matrix parts that were formed by the soft segments. Inclusions of hard segments, likely formed by better ordering in the polymer, can be seen in some limited areas.

The CAs of water on the surface of the films were measured at normal temperature and pressure, and the obtained results are shown in Figure 8 and Table 2. In particular, Figure 8 shows the CAs of PUE-PTMG-CD $D_{0-5}$. The CAs of the $\beta$-CD-based PUEs increased as their $\beta$-CD content increased. Similar to PUEPTMG-CD $D_{0-5}$, the CAs of PUE-PCL-CD $D_{0-5}$ and PUE-PCD-CD $D_{0-5}$ increased as their $\beta$-CD content increased (Table 2). Increases in $\beta$-CD content could weaken the ability of the PUE surface to generate hydrogen bonds with water molecules, thereby increasing the surface hydrophobic properties of the resultant PUEs with increasing $\beta$-CD content.

\subsection{Chemical Properties}

The solvent resistances of the PUEs (PUE-PTMG-CD ${ }_{0-5}$, PUE-PCL-CD ${ }_{0-5}$, and PUE-PCD-CD $\mathrm{CD}_{0-5}$ ) were tested by immersing each PUE film in various solvents, including benzene, hexane, acetone, THF, DMF, and DMSO; the results are presented in Table 3. All of the PUEs were resistant to hexane and swelled in benzene, acetone, DMF, and DMSO at room temperature $\left(23^{\circ} \mathrm{C} \pm 2^{\circ} \mathrm{C}\right)$. PUEPTMG- $\mathrm{CD}_{0}$ dissolved completely in THF. While all of the $\beta$-CD-containing PUEs swelled significantly in DMF and DMSO at $100^{\circ} \mathrm{C}$, PUE-PTMG-CD ${ }_{1}$, PUE-PCL-CD $D_{1}$, and PUE-PCD-CD ${ }_{1}$ showed slight dissolution only. PUEs without $\beta$-CD dissolved in DMF and DMSO at $100^{\circ} \mathrm{C}$. In general, the PUEs with $\beta$-CD exhibited good solvent resistance. 


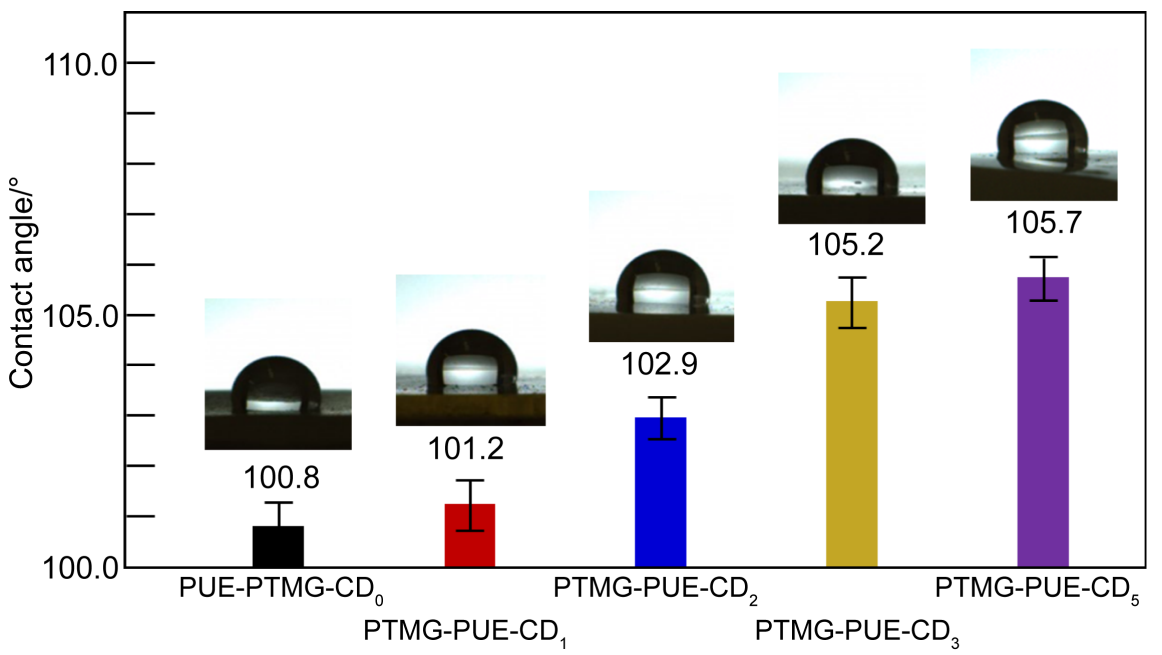

Figure 8. Contact angle micrographs of a water droplet on PUEs with $\beta$-CD. $\beta$-CD content: PUE-PTMG-CD $00 \mathrm{wt} \%$; PUE-PTMG-CD ${ }_{1}=1 \mathrm{wt} \%$; PUE-PTMG-CD $=2 \mathrm{wt} \%$; PUE-PTMG-CD $3=3 \mathrm{wt} \%$; PUE-PTMG-CD $5=5 \mathrm{wt} \%$.

Table 2. Contact angle micrographs of a water droplet on PUEs with $\beta$-CD.

\begin{tabular}{cccccc}
\hline Sample & $\boldsymbol{\theta}(\mathrm{deg})$ & & $\boldsymbol{\theta}(\mathrm{deg})$ & & $\boldsymbol{\theta}(\mathrm{deg})$ \\
\hline PUE-PTMG-CD & 100.8 & PUE-PCL-CD & 103.6 & PUE-PCD-CD $_{0}$ & 103.6 \\
PUE-PTMG-CD & 101.2 & PUE-PCL-CD & 106.8 & PUE-PCD-CD $_{1}$ & 103.8 \\
PUE-PTMG-CD & 102.9 & PUE-PCL-CD & 107.5 & PUE-PCD-CD & 100.5 \\
PUE-PTMG-CD & 105.2 & PUE-PCL-CD & 107.3 & PUE-PCD-CD $_{3}$ & 104.7 \\
PUE-PTMG-CD & 105.7 & PUE-PCL-CD & 110.4 & PUE-PCD-CD $_{5}$ & 105.9 \\
\hline
\end{tabular}

Table 3. Solubilities of PUEs with $\beta$-CD.

\begin{tabular}{|c|c|c|c|c|c|c|c|c|}
\hline \multirow{2}{*}{ Sample } & \multirow{2}{*}{ Benzene } & \multirow{2}{*}{ Hexane } & \multirow{2}{*}{ Acetone } & \multirow{2}{*}{ THF } & \multicolumn{2}{|c|}{ DMF } & \multicolumn{2}{|c|}{ DMSO } \\
\hline & & & & & $23^{\circ} \mathrm{C}$ & $100^{\circ} \mathrm{C}$ & $23^{\circ} \mathrm{C}$ & $100^{\circ} \mathrm{C}$ \\
\hline PUE-PTMG-CD 0 & $\square$ & $x$ & $\square$ & 0 & $\square$ & 0 & $\square$ & 0 \\
\hline PUE-PTMG-CD & $\square$ & $x$ & $\square$ & $\square$ & $\square$ & $\triangle$ & $\square$ & $\triangle$ \\
\hline PUE-PTMG-CD ${ }_{2}$ & $\square$ & $x$ & $\square$ & $\square$ & $\square$ & $\square$ & $\square$ & $\square$ \\
\hline PUE-PTMG-CD 3 & $\square$ & $x$ & $\square$ & $\square$ & $\square$ & $\square$ & $\square$ & $\square$ \\
\hline PUE-PTMG-CD 5 & $\square$ & $\times$ & $\square$ & $\square$ & $\square$ & $\square$ & $\square$ & $\square$ \\
\hline PUE-PCL-CD 0 & $\square$ & $x$ & $\square$ & $\square$ & $\square$ & O & $\square$ & O \\
\hline PUE-PCL-CD ${ }_{1}$ & $\square$ & $x$ & $\square$ & $\square$ & $\square$ & $\triangle$ & $\square$ & $\triangle$ \\
\hline PUE-PCL-CD 2 & $\square$ & $x$ & $\square$ & $\square$ & $\square$ & $\square$ & $\square$ & $\square$ \\
\hline PUE-PCL-CD 3 & $\square$ & $x$ & $\square$ & $\square$ & $\square$ & $\square$ & $\square$ & $\square$ \\
\hline PUE-PCL-CD ${ }_{5}$ & $\square$ & $x$ & $\square$ & $\square$ & $\square$ & $\square$ & $\square$ & $\square$ \\
\hline PUE-PCD-CD 0 & $\square$ & $x$ & $\square$ & $\square$ & $\square$ & O & $\square$ & O \\
\hline PUE-PCD-CD & $\square$ & $x$ & $\square$ & $\square$ & $\square$ & $\triangle$ & $\square$ & $\triangle$ \\
\hline PUE-PCD-CD ${ }_{2}$ & $\square$ & $x$ & $\square$ & $\square$ & $\square$ & $\square$ & $\square$ & $\square$ \\
\hline PUE-PCD-CD 3 & $\square$ & $x$ & $\square$ & $\square$ & $\square$ & $\square$ & $\square$ & $\square$ \\
\hline PUE-PCD-CD 5 & $\square$ & $x$ & $\square$ & $\square$ & $\square$ & $\square$ & $\square$ & $\square$ \\
\hline
\end{tabular}

O: completely dissolved, $\triangle$ : slightly dissolved, $\square$ : swelled, $\times$ : undissolved. ${ }^{\text {a }}$ Polyol: polyoxytetramethylene glycol (molecular weight = 1000; PTMG; PCL; PCD). ${ }^{b}$ Measurement conditions: benzene, hexane, acetone, THF, DMF or DMSO as the solvent at room temperature $\left(23^{\circ} \mathrm{C} \pm 2^{\circ} \mathrm{C}\right.$ ) or $100^{\circ} \mathrm{C}$ (for DMF and DMSO) for $24 \mathrm{~h}$. ${ }^{\circ}$ Room temperature $\left(23^{\circ} \mathrm{C} \pm 2^{\circ} \mathrm{C}\right) .{ }^{\mathrm{d}}$ Room temperature $\left(23^{\circ} \mathrm{C} \pm 2^{\circ} \mathrm{C}\right)$ and $100^{\circ} \mathrm{C}$. 
Swelling tests were performed to confirm the addition of $\beta$-CD as a crosslinker. Table 4 reveals that the swelling rates of PUE-PTMG-CD $D_{0-5}$, PUE-PCL$\mathrm{CD}_{0-5}$, and PUE-PCD-CD $\mathrm{CD}_{0-5}$ decreased as their $\beta$-CD content increased. This result confirms an increase in crosslinking density with increasing $\beta$-CD content. However, the film of PUE-PTMG without $\beta$-CD is nearly soluble.

The hardness of the PUEs is shown in Table 4. Crosslinking with $\beta$-CD obviously decreased the hardness of the PUEs with $\beta$-CD. For example, the hardness of PUEs-PCD-CD ${ }_{1-5}$ is apparently higher than those of PUEs-PTMG-CD $D_{1-5}$ and PUEs-PCL-CD ${ }_{1-5}$. Steric hindrance reduces the mobility of the molecular chains in PUEs-CD-CD $D_{1-5}$ and results in increased hardness and toughness.

\subsection{Mechanical Properties}

The stress-strain curves of the PUEs are shown in Figure 9, and their tensile strength and elongation at break are shown in Table 5 . In comparison with the PUEs without $\beta$-CD, The PUEs with $\beta$-CD showed much lower elongation at break and strength values, corresponding to poorer elasticity. PUEs with $1 \%$ $\beta$-CD content showed much higher strength than PUEs with higher $\beta$-CD contents. PUE-PTMG-CD ${ }_{1}$ revealed a much higher elongation at break and strength than the other $\beta$-CD-based PUEs, and PUE-PCD-CD ${ }_{0-5}$ nearly completely lost its

Table 4. Physical properties of PUEs with $\beta$-CD.

\begin{tabular}{|c|c|c|c|c|c|}
\hline Sample & Hardness $^{\mathrm{a}}$ (JIS A) & Swelling rate ${ }^{\mathrm{b}}(\%)$ & $\operatorname{Tg}^{\mathrm{c}}\left({ }^{\circ} \mathrm{C}\right)$ & $\mathrm{T}_{5}^{\mathrm{d}}\left({ }^{\circ} \mathrm{C}\right)$ & $\mathrm{T}_{50}^{\mathrm{d}} \quad\left({ }^{\circ} \mathrm{C}\right)$ \\
\hline PUE-PTMG-CD 0 & 86 & Soluble & -53.6 & 306 & 403 \\
\hline PUE-PTMG-CD & 83 & 410 & -50.7 & 306 & 395 \\
\hline PUE-PTMG-CD 2 & 81 & 370 & -50.9 & 312 & 421 \\
\hline PUE-PTMG-CD 3 & 80 & 340 & -51.0 & 314 & 415 \\
\hline PUE-PTMG-CD 5 & 80 & 341 & -49.6 & 317 & 415 \\
\hline PUE-PCL-CD 0 & 84 & 628 & -56.9 & 303 & 322 \\
\hline PUE-PCL-CD 1 & 76 & 409 & -50.1 & 313 & 333 \\
\hline PUE-PCL-CD 2 & 78 & 393 & -43.6 & 313 & 330 \\
\hline PUE-PCL-CD 3 & 80 & 377 & -40.4 & 307 & 325 \\
\hline PUE-PCL-CD 5 & 77 & 370 & -30.9 & 308 & 327 \\
\hline PUE-PCD-CD 0 & 87 & 705 & -20.1 & 310 & 377 \\
\hline PUE-PCD-CD & 82 & 331 & -15.2 & 308 & 358 \\
\hline PUE-PCD-CD 2 & 83 & 370 & -11.5 & 312 & 358 \\
\hline PUE-PCD-CD 3 & 84 & 300 & -14.0 & 307 & 352 \\
\hline PUE-PCD-CD 5 & 83 & 310 & -14.0 & 307 & 357 \\
\hline
\end{tabular}

${ }^{\mathrm{a}}$ Measurement conditions: JIS A type, total thickness $=6 \mathrm{~mm}$, room temperature $\left(23^{\circ} \mathrm{C} \pm 2{ }^{\circ} \mathrm{C}\right) .{ }^{\mathrm{b}}$ Measurement condition: THF solvent at room temperature $\left(23^{\circ} \mathrm{C} \pm 2^{\circ} \mathrm{C}\right)$ for $24 \mathrm{~h}$. ${ }^{\circ}$ Differential scanning calorimetry was performed at heating rate of $10^{\circ} \mathrm{C} / \mathrm{min}$ from $-100^{\circ} \mathrm{C}$ to $300^{\circ} \mathrm{C}$ under an Ar atmosphere. ${ }^{\mathrm{d}}$ Thermogravimetric analysis was performed at a heating rate of $10^{\circ} \mathrm{C} / \mathrm{min}$ from $30^{\circ} \mathrm{C}$ to $500^{\circ} \mathrm{C}$ under an $\mathrm{Ar}$ atmosphere. 


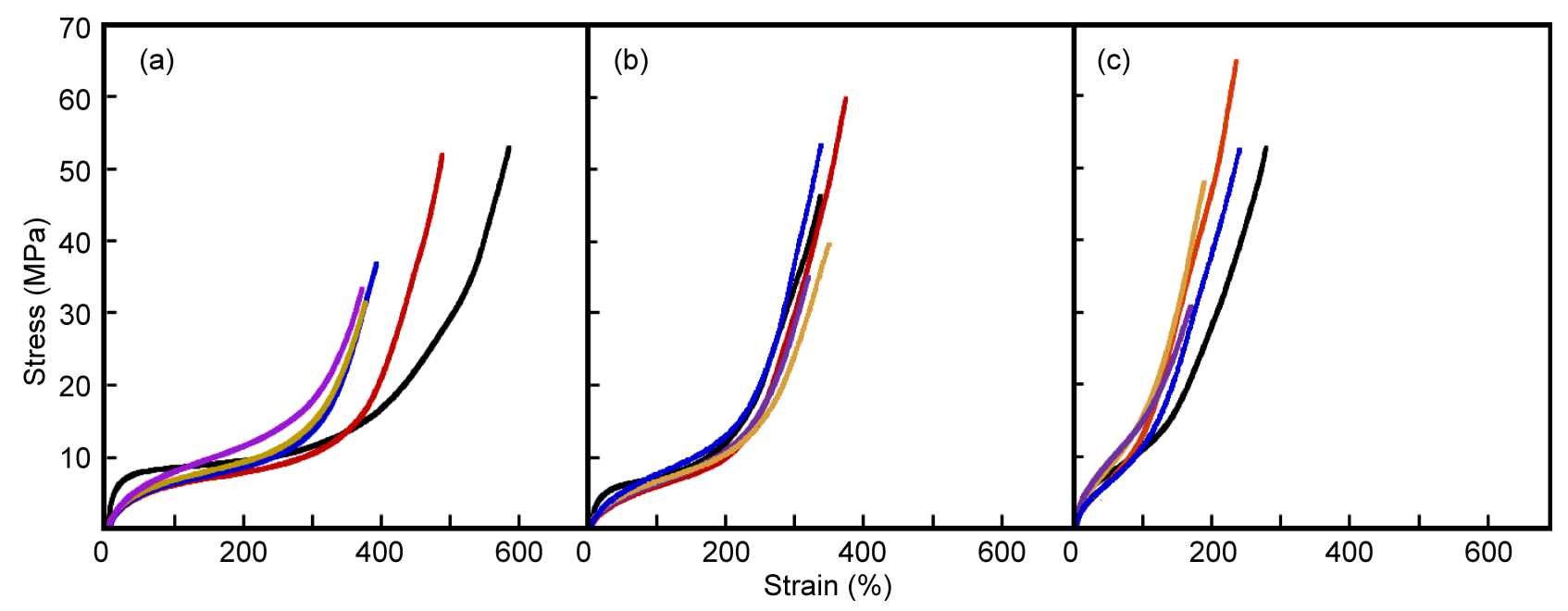

Figure 9. Stress-strain curves of PUEs with $\beta$-CD. (a) PUE-PTMG; (b) PUE-PCL; (c) PUE-PCD. $\beta$-CD content: black = 0 wt\%; red $=1 \mathrm{wt} \%$; blue $=2 \mathrm{wt} \%$; yellow $=3 \mathrm{wt} \%$; purple $=5 \mathrm{wt} \%$.

Table 5. Tensile properties of PUEs with $\beta$-CD.

\begin{tabular}{|c|c|c|c|c|c|c|c|c|}
\hline \multirow{2}{*}{ Sample $^{a}$} & $\sigma 10$ & $\sigma 50$ & $\sigma 100$ & $\sigma 200$ & $\sigma 300$ & $\sigma 400$ & $\sigma^{\mathrm{b}}$ & $\mathrm{Eb}^{\mathrm{c}}$ \\
\hline & $(\mathrm{MPa})$ & $(\mathrm{MPa})$ & $(\mathrm{MPa})$ & $(\mathrm{MPa})$ & $(\mathrm{MPa})$ & $(\mathrm{MPa})$ & $(\mathrm{MPa})$ & $(\%)$ \\
\hline PUE-PTMG-CD & 4.43 & 6.86 & 7.69 & 9.46 & 14.6 & 32.0 & 50.5 & 448 \\
\hline PUE-PTMG-CD ${ }_{1}$ & 1.45 & 4.22 & 5.74 & 7.42 & 10.1 & 20.9 & 51.4 & 587 \\
\hline PUE-PTMG-CD ${ }_{2}$ & 1.77 & 4.62 & 6.17 & 8.40 & 13.7 & - & 36.5 & 389 \\
\hline PUE-PTMG-CD 3 & 1.70 & 4.61 & 6.34 & 8.80 & 14.5 & - & 30.9 & 374 \\
\hline PUE-PTMG-CD 5 & 1.86 & 5.43 & 7.70 & 11.2 & 17.9 & - & 33.0 & 368 \\
\hline PUE-PCL-CD 0 & 3.76 & 6.08 & 7.15 & 12.4 & 35.0 & - & 48.8 & 376 \\
\hline PUE-PCL-CD 1 & 1.40 & 3.79 & 5.63 & 9.84 & 31.1 & - & 59.2 & 369 \\
\hline PUE-PCL-CD 2 & 1.95 & 5.11 & 7.50 & 13.1 & 39.2 & - & 40.0 & 329 \\
\hline PUE-PCL-CD 3 & 1.49 & 4.16 & 6.10 & 10.0 & 24.9 & - & 38.7 & 344 \\
\hline PUE-PCL-CD 5 & 0.20 & 3.77 & 5.75 & 10.3 & 28.6 & - & 34.2 & 317 \\
\hline PUE-PCD-CD 0 & 3.87 & 5.99 & 6.85 & 9.87 & 21.2 & - & 52.5 & 273 \\
\hline PUE-PCD-CD 1 & 2.37 & 6.36 & 13.4 & 48.0 & - & - & 64.3 & 231 \\
\hline PUE-PCD-CD 2 & 2.38 & 6.16 & 11.5 & 39.2 & - & - & 51.8 & 234 \\
\hline PUE-PCD-CD 3 & 3.47 & 8.47 & 16.1 & - & - & - & 47.3 & 183 \\
\hline PUE-PCD-CD 5 & 3.69 & 8.96 & 14.9 & - & - & - & 30.1 & 166 \\
\hline
\end{tabular}

${ }^{a}$ Tensile properties measured at room temperature $\left(23^{\circ} \mathrm{C} \pm 2{ }^{\circ} \mathrm{C}\right)$ with stain speed of $100 \mathrm{~mm} / \mathrm{min}$. ${ }^{\mathrm{b}} \mathrm{Tensile}$ strength at breaking point. ${ }^{\mathrm{C}}$ Elongation at breaking point.

elasticity. Besides the HS/SS or HD/SD ratio, the balance between stiffness and flexibility must also be controlled when synthesizing PUEs with $\beta$-CD.

\subsection{Thermal Properties}

The DSC curves of PUE-PTMG-CD $D_{0-5}$, PUE-PCL-CD ${ }_{0-5}$, and PUE-PCD-CD $\mathrm{CD}_{0-5}$ 
are reported in Table 4. The Tgs of PUEs with $\beta$-CD increased in comparison with those of the corresponding PUEs without $\beta$-CDas their $\beta$-CD content increased. The Tgs of the $\beta$-CD-based PUEs are influenced by the crosslinking density and chemical structure of the polymer. In general, the Tgs of soft segments increase with increasing hard-segment concentration and the number of crosslinks added, likely because steric hindrance brought about by the formation of physical and chemical crosslinks between molecular chains limits the local motion of polymer segments.

Figure 10 shows the viscoelastic behaviors of the PUEs in terms of storage modulus ( $\left.\mathrm{E}^{\prime}\right)$ and $\tan \delta\left(\tan \delta=\mathrm{E}^{\prime \prime} / \mathrm{E}^{\prime}\right)$. PUEs without $\beta$-CD content, including PUE-PTMG-CD $D_{0}$ and PUE-PCL-CD ${ }_{0}$, demonstrated a fairly long and temperature-insensitive rubbery plateau extending up to about $+150^{\circ} \mathrm{C}$ with a modulus of about $1 \times 10^{8} \mathrm{~Pa}$. These polymers showed flow between $+150^{\circ} \mathrm{C}$ and $+250^{\circ} \mathrm{C}$. By contrast, PUE-PCD- $\mathrm{CD}_{0}$ revealed a short and temperature-insensitive rubbery plateau extending up to about $+50^{\circ} \mathrm{C}$, with a modulus of about $1 \times 10^{8} \mathrm{~Pa}$. The PUEs with $\beta$-CD showed highly similar thermomechanical behaviors, indicating a strong dependence on hard-segment formation and hydrogen-bond strength. PUE-PTMG-CD ${ }_{1-5}$ and PUE-PCL-CD $D_{1-5}$ displayed a temperature-insensitive rubbery plateau extending to $+150^{\circ} \mathrm{C}$ with a modulus of about $3 \times 10^{7}$ $\mathrm{Pa}$. The polymers showed fairly good integrity at higher temperatures with modulus values of about $2 \times 10^{7} \mathrm{~Pa}$, as well as flow between $+150^{\circ} \mathrm{C}$ and $+250^{\circ} \mathrm{C}$. PUE-PCD-CD ${ }_{1-5}$ demonstrated a short and temperature-insensitive rubbery plateau extending up to about $+50^{\circ} \mathrm{C}$, with a modulus of about $1 \times 10^{7} \mathrm{~Pa}$; the

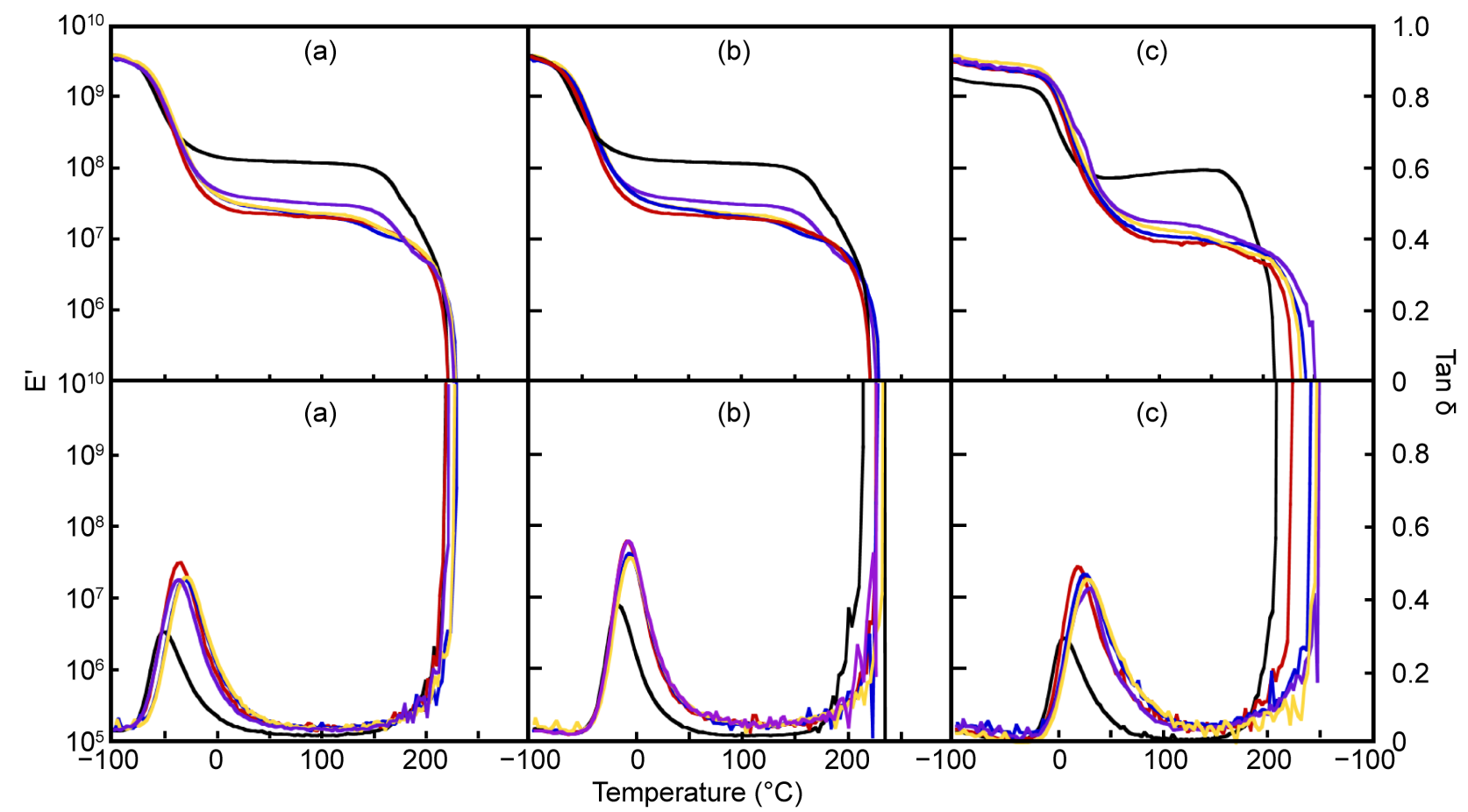

Figure 10. Storage modules and tan $\delta$-temperature curves of PUEs. (a) PUE-PTMG; (b) PUE-PCL; (c) PUE-PCD. $\beta$-CD content: black $=0 \mathrm{wt} \%$; red $=1 \mathrm{wt} \%$; blue $=2 \mathrm{wt} \%$; yellow $=3 \mathrm{wt} \%$; purple $=5 \mathrm{wt} \%$. 
polymer also showed flow between $+150^{\circ} \mathrm{C}$ and $+250^{\circ} \mathrm{C}$. These results suggest that the PUEs exhibit much more crosslink structure and their molecular chains could move more easily at a higher temperature than at the glass transition temperature (Tg). Previous research [32] indicates that the hydrogen bonding decreased as temperature increases because the hydrogen bonding is related to the $\mathrm{Tg}$ of the hard segments. About $40 \%$ of hydrogen bonding persists at $200^{\circ} \mathrm{C}$.

The TGA curves of the PUEs with and without $\beta$-CD are shown in Table 4. All of the PUEs were thermally stable up to around $280^{\circ} \mathrm{C}$ and began to lose weight at higher temperatures. The $5 \%$ weight loss temperatures $\left(\mathrm{T}_{5 \mathrm{~S}}\right)$ of the $\beta$ CD-based PUEs were nearly identical to those of the PUEs without $\beta$-CD, and the $50 \%$ weight loss temperatures $\left(\mathrm{T}_{50 \mathrm{~s}}\right)$ of PUE-PTMG-CD $\mathrm{D}_{1-5}$ and PUE-PCL$\mathrm{CD}_{1-5}$ were slightly higher than those of the corresponding PUEs without $\beta$-CD. By contrast, the T50s of PUE-PCD-CD ${ }_{1-5}$ were lower than those of the corresponding PUEs without $\beta$-CD. In general, as the decomposition of PUE is believed to occur via dissociation of the urethane linkage toisocyanate and alcohol at $200^{\circ} \mathrm{C}-300^{\circ} \mathrm{C}$ and polyol degradation at above $350^{\circ} \mathrm{C}$, PUEs with $\beta$-CD content are clearly more thermal stable than those without.

\section{Conclusion}

A series of $\beta$-CD crosslinked PUEs were synthesized from different polyols. The polyols applied affected the properties of the resultant PUEs to a significant extent. Use of a polyol with comparatively regular molecular chains, such as PTMG, resulted in $\beta$-CD-based PUEs with acceptable properties. By contrast, use of a polyol with low chain regularity, such as PCD, led to $\beta$-CD-based PUEs with poor elasticity. The PUEs which were crosslinked from $\beta$-CD and prepolymer with low regularity are harder and firmer.

\section{Acknowledgements}

The authors are grateful to the testing Center of Yangzhou University for providing access to the SEM and AFM instruments.

\section{References}

[1] Hapburn, C. (1991) Polyurethane Elastomers. Elsevier, Oxford, 1.

[2] Oertel, G. (1985) Polyurethane Handbook. Hanser Publishers, Munich, 161.

[3] Szycher, M. (1999) Szycher's Handbook of Polyurethanes. CRC Press, New York.

[4] Wirtz, H. and Schulte, K. (1973) Processing of Polyurethane Foam Systems. Kunststoffe, 63, 726-730.

[5] Avar, G., Meier, W.U., Casselmann, H. and Achten, D. (2012) Polymer Science: A Comprehensive Reference. Polymer Science: A Comprehensive Reference, 10, 411441.

[6] Kuehn, A.F. (1986) Polyurethane a Promising Prospect in Roll Coverings. PIMA, 68, 27-28.

[7] Bez, W. and Quack, G. (1983) Polyurethane and Latex Foam Carpet Backing Today. Cellular Polymers, 2, 31-53. 
[8] Gagro, D. (2010) Polyurethanes Overview of the PUR Market. European Coatings Journal, 10, 9-11.

[9] Hare, C.H. (2000) A Review of Polyurethanes: Formulation Variables and Their Effects on Performance. Journal of Protective Coatings and Linings, 17, 34-44.

[10] Walter, R.F. (1969) Sucrose-Ethylene Diamine Polyols and Process for Preparing Same. US Patent No. 3640997.

[11] Neil, H.N. (1978) Sucrose Based Polyether Polyols. US Patent No. 4230824.

[12] Hatakeyama, H., Hirose, S. and Hatakeyama, T. (1995) Biodegradable Polyurethanes from Plant Components. Journal of Macromolecular Science, Pure and Applied Chemistry, A32, 743-750. https://doi.org/10.1080/10601329508010285

[13] Asano, Y. and Hatakeyama, H. (2003) Rigid Type Polyurethane Foams Containing Saccharide and Lignin Structures in the Molecular Chain. Memoirs of Fukui University of Technology, 33, 275-282.

[14] Hatakeyama, H. and Hatakeyama, T. (2005) Environmentally Compatible Hybrid Type Polyurethane Foams Containing Saccharide and Lignin Components. Macromolecular Symposia, 224, 219-226. https://doi.org/10.1002/masy.200550619

[15] Chen, Q., Li, R., Sun, K., Li, J. and Liu, C. (2011) Preparation of Bio-Degradable Polyurethane Foams from Liquefied Wheat Straw. Advanced Materials Research, 217, 1239-1244. https://doi.org/10.4028/www.scientific.net/AMR.217-218.1239

[16] Wang, G. and Zhou, A. (2011) Soy Protein Based Biodegradable Flexible Polyurethane Foam. Advanced Materials Research, 152, 1862-1865. https://doi.org/10.4028/www.scientific.net/AMR.264-265.1862

[17] Garcon, R., Clerk, C., Gesson, J.-P., Bordado, J., Nunes, T., Caroco, S., Gomes, P.T., Minas da Piedade, M.E. and Rauter, A.P. (2001) Synthesis of Novel Polyurethanes from Sugars and 1,6-Hexamethylene Diisocyanate. Carbonhydrateo Polymer, 45, 123-127.

[18] Lim, H., Kim, E.Y. and Kim, B.K. (2010) Polyurethane Foams Blown with Various Types of Environmentally Friendly Blowing Agents. Plastics, Rubber and Composites, 39, 364-369. https://doi.org/10.1179/174328910X12691245469835

[19] Ionescu, M., Mihalache, I., Zugravu, V. and Mihai, S. (1994) Inherently Flame Retardant Rigid Polyurethane Foams Based on New Triazinic Polyether Polyols. Cellular Polymers, 13, 57-68.

[20] Guo, A., Demydov, D., Zhang, W., Zoran, W. and Petrovie, S. (2002) Polyols and Polyurethanes from Hydroformylation of Soybean Oil. Journal of Polymers and the Environment, 10, 49-52. https://doi.org/10.1023/A:1021022123733

[21] Dhanjay, J. and Alain, D. (1997) Sucrose-Based Polymers: Polyurethanes with Sucrose in the Main Chain. European Polymer Journal, 33, 1577-1582.

[22] Foote, J.F., Le, B.L.R. and Marco, W. (1966) US Patent 3265641.

[23] Mir, G., Sadeghi, M., Shamsi, R. and Sayaf, M. (2011) From Aminolysis Product of PET Waste to Novel Biodegradable Polyuretuhanes. Journal of Polymers and the Environment, 19, 522-534. https://doi.org/10.1007/s10924-011-0283-7

[24] Kim, S.H., Lim, H. and Kim, B.K. (2008) Effects of Initiator Type in Rigid Polyurethane Foams. Polmer Engineering and Science, 48, 1518-1523.

https://doi.org/10.1002/pen.21122

[25] Kim, B.K. and Paik, S.H. (1999) UV-Curable Poly-(ethylene glycol)-Based Polyurethane Acrylate Hydrogel. Journal of Polymer Science Part A, 37, 2703-2709. https://doi.org/10.1002/(SICI)1099-0518(19990801)37:15<2703::AID-POLA3>3.0.C $\underline{\mathrm{O} ; 2-\mathrm{A}}$ 
[26] Laijiu, Z., Bing, D. and Zeshou, H. (2013) Treatment of Wool Scouring Wastewater by Immobilized Chitosan Bio-Membrane. Journal of Engineered Fibers and Fabrics, 8, 1-5.

[27] Pan, X. and Webster, D.C. (2012) New Biobased High Functionality Polyols and Their Use in Polyurethane Coatings. ChemSusChem, 5, 419-429. https://doi.org/10.1002/cssc.201100415

[28] Deka, H. and Karak, N. (2009) Bio-Based Hyperbranched Polyurethanes for Surface Coating Applications. Progress in Organic Coatings, 66, 192-198.

[29] Hasirci, N. and Aksoy, E.A. (2007) Synthesis and Modifications of Polyurethanes for Biomedical Purposes. High Performance Polymer, 19, 621-637. https://doi.org/10.1177/0954008307081203

[30] Yeganeh, H., Jamshidi, H. and Jamshidi, S. (2007) Synthesis and Properties of Novel Biodegradable Poly-(-capro-lactone)/Poly(ethylene glycol)-Based Polyurethane Elastomers. Polymer International, 56, 41-49. https://doi.org/10.1002/pi.2107

[31] Xie, A., Zhang, M. and Inoue, S. (2016) Influence of $\beta$-Cyclodextrin on Morphologies and Chemical, Thermal, and Mechanical Properties of Non-Chain Extended Polyurethane Elastomers. Journal of Polymer Research, 23, 145. https://doi.org/10.1007/s10965-016-1046-x

[32] Xie, A., Zhang, M. and Inoue, S. (2016) Influence of Diisocyanate on Polyurethane Elastomers which Cross-linked by $\beta$-Cyclodextrin. Open Journal of Organic Polymer Materials, 6, 99-111. https://doi.org/10.4236/ojopm.2016.63010

[33] Xie, A., Ji, X., Chen, Y., Zhang, M. and Inoue, S. (2016) Nanoindentation Measurements of Mechanical Properties of Polyurethane Elastomers Which Cross Linked by $\beta$-Cyclodextrin. Open Journal of Organic Polymer Materials, 6, 112-118. https://doi.org/10.4236/ojopm.2016.63011

\section{Submit or recommend next manuscript to SCIRP and we will provide best} service for you:

Accepting pre-submission inquiries through Email, Facebook, LinkedIn, Twitter, etc. A wide selection of journals (inclusive of 9 subjects, more than 200 journals)

Providing 24-hour high-quality service

User-friendly online submission system

Fair and swift peer-review system

Efficient typesetting and proofreading procedure

Display of the result of downloads and visits, as well as the number of cited articles

Maximum dissemination of your research work

Submit your manuscript at: http://papersubmission.scirp.org/

Or contact ojopm@scirp.org 